white paper. ${ }^{27}$ Future research may have the challenging task of evaluating the effectiveness of combining specific clinical interventions within or without a protective legal framework.

The UK700 Group is a collaborative study team involving four clinical centres. Manchester: Tom Butler, Francis Creed, Janelle Fraser, Peter Huxley, Nicholas Tarrier, Theresa Tattan. King's/ Maudsley, London: Tom Fahy, Karyna Gilvarry, Kwame McKenzie, Robin Murray, Jim van Os, Elizabeth Walsh. St Mary's/St Charles' Hospitals, London: John Green, Anna Higgitt, Elizabeth van Horn, Donal Leddy, Catherine Manley, Patricia Thornton, Peter Tyrer. St George's Hospital, London: Rob Bale, Tom Burns, Matthew Fiander, Kate Harvey, Andy Kent, Chiara Samele. York (health economics): Sarah Byford, David Torgerson, Ken Wright. London School of Hygiene and Tropical Medicine (statistical centre): Simon Thompson, Ian White.

Funding: EW was funded by a Wellcome Training Fellowship. The UK700 trial was funded by grants from the Department of Health and NHS research and development programme.

Competing interests: None declared.

1 Monahan J. Mental disorder and violent behaviour: perceptions and evidence. Am Psychol 1992;47:511-21.

2 Swartz MS, Swanson JW, Hiday VA, Borum R, Wagner HR, Burns BJ. Violence and severe mental illness. The effects of substance abuse and nonadherence to medication. Am J Psychiatry 1998;155:226-31.

3 Silver E, Mulvey EP, Monahan J. Assessing violence risk among discharged psychiatric patients: toward an ecological approach. Law Hum Behav 1999;23:237-55

4 Department of Health. The care programme approach for people with a mental illness referred to the specialist psychiatric services. London: Department of Health, 1990.

5 UK700 Group. Intensive versus standard case management for severe psychotic illness: a randomised trial. Lancet 1999;353:2185-9.

6 Spitzer R, Endicott J, Robins E. Research diagnostic criteria: rationale and reliability. Arch Gen Psychiatry 1978;35:773-82.

7 Burns T, Fiander M, Kent A, Ukoumunne OC, Byford S, Fahy T, et al. Effects of case-load size on the process of care of patients with severe psychotic illness. Br J Psychiatry 2000;177:427-33.

8 World Health Organization. The life chart. Geneva: WHO, 1992

9 Asberg M, Montgomery SA, Perris C. The CPRS-development and applications of a psychiatric rating scale. Acta Psychiatr Scand 1978;271 (suppl):5-27.

10 Andreason NC. Modified scale for the assessment of negative symptoms. Iowa City: University of Iowa, 1984
11 Phelan M, Slade M, Thornicroft G, Dunn G, Holloway F, Wykes T, et al. The Camberwell assessment of need: the validity and reliability of an instrument to assess the needs of people with severe mental illness. $\mathrm{Br} \mathrm{J}$ Psychiatry 1995; 167:589-95.

12 Buchanan A. The investigation of acting on delusions as a tool for risk assessment in the mentally disordered. Br J Psychiatry 1997;170(suppl 32):12-6.

13 Swanson JW, Borum R, Swartz M, Hiday V. Violent behaviour preceding hospitalisation among persons with severe mental illness. Law Hum Behav 1999;23:185-204.

14 Hodgins S. Mental disorder, intellectual deficiency, and crime. Evidence from a birth cohort. Arch Gen Psychiatry 1992;49:476-83.

15 Mulvey EP, Shaw E, Lidz CW. Why use multiple sources in research on patient violence in the community? Crim Behav Mental Health $1994 ; 4: 253-8$

16 Elliott D, Huizinga D, Morse B. Self-reported violent offending: a descriptive analysis of juvenile violent offenders and their offending careers. $J$ Interpersonal Viol 1986;1:472-513.

17 Steadman H, Mulvey EP, Monahan J, Robbins PC, Applebaum PS, Grisso $\mathrm{T}$, et al. Violence by people discharged from acute psychiatric inpatient facilities and by others in the same neighborhoods. Arch Gen Psychiatry 1998:55:1-9.

18 Monahan J. Clinical and actuarial predictions of violence. In: Faigman D, Kaye D, Saks M, Sanders J, eds. Modern scientific evidence: the law and science of expert testimony. Vol 1. St Paul, MN: West Publishing Company, 1997:300-18.

19 Chandler D, Meisel J, McGowen M, Mintz J, Madison K. Client outcomes in two model capitated integrated service agencies. Psychiatr Serv $1996 ; 47: 175-80$.

20 Bond GR, Miller LD, Krumwied RD, Ward RS. Assertive case management in three CMHCs: a controlled study. Hosp Community Psychiatry 1988;39:411-8.

21 Bond GR, Witheridge TF, Dincin J, Wasmer D, Webb J, De Graaf-Kaser R. Assertive community treatment for frequent users of psychiatric hospitals in a large city: a controlled study. Am J Community Psychol 1990;18:865-91.

22 Lehman AF, Dixon LB, Kernan E, DeForge B. A randomised trial of assertive community treatment for homeless persons with severe mental illness. Arch Gen Psychiatry 1997;54:1038-43.

23 Solomon P, Draine J. The efficacy of a consumer case management team: 2-year outcomes of a randomised trial. J Mental Health Admin $1995 ; 22: 126-34$

24 Stein LI, Test MA. Alternative to mental hospital treatment: 1. Conceptual model, treatment program, and clinical evaluation. Arch Gen Psychiatry 1980;37:392-7.

25 Test MA. Training in community living. In: Liberman RP, ed. Handbook of psychiatric rehabilitation. New York: Macmillan, 1992

26 Swanson JW, Swartz MS, Borum R, Hiday VA, Wagner HR, Burns BJ. Involuntary out-patient commitment and reduction of violent behaviour in persons with severe mental illness. Br J Psychiatry 2000;176:324-31.

27 Secretary of State for Health. Reforming the Mental Health Act. London: Stationery Office, 2000

(Accepted 23 July 2001)

\title{
Impact of Effective Health Care bulletin on treatment of persistent glue ear in children: time series analysis
}

\author{
James Mason, Nick Freemantle, George Browning
}

Centre for Services Research, University of Newcastle upon Tyne, Newcastle upon Tyne

NE2 4AA

James Mason professor of health economics

continued over

BMJ 2001;323:1096-7
During the 1980s, surgery for chronic otitis media with effusion (glue ear) increased greatly without obvious reason. "Dry taps"-absence of effusion upon incision-were common, probably because the surgery was performed without the surgeon confirming that the condition had not already resolved. ${ }^{2}$ An Effective Health Care bulletin on the treatment of persistent glue ear in children was distributed nationally to NHS decision makers in 1992. ${ }^{2}$ Based on systematic review, the bulletin concluded that surgery should be restricted to children with an extended period of substantial hearing impairment, with persistence and severity established by watchful waiting. We evaluated surgery rates before and after distribution of the bulletin.

\section{Methods and results}

Quarterly numbers of D151 procedures-insertion of a ventilation tube through the tympanic membraneperformed in children aged under 15 in England from
1989 to 1996 were obtained from the hospital episodes system. We calculated per capita regional and national rates for this procedure. ${ }^{3}$

We applied a generalised linear model with a heterogeneous first order autoregressive structure and repeated measures by region. The effect of the introduction of the bulletin was nested into the model using 'proc mixed' in SAS version 8 (SAS Institute, Cary, NC). This approach consistently identifies the best autoregressive structure (the model adjusts for the relatedness of sequential observations over time). We investigated regional variations in surgical rates by comparing standard error terms from the model before and after distribution of the bulletin. Overall, the model included data from 14 regions, each of which provided results from 28 quarters, half before and half after distribution of the bulletin.

In 1992, 77766 grommet insertions were conducted; this was equivalent to a quarterly rate of 2.1 per 


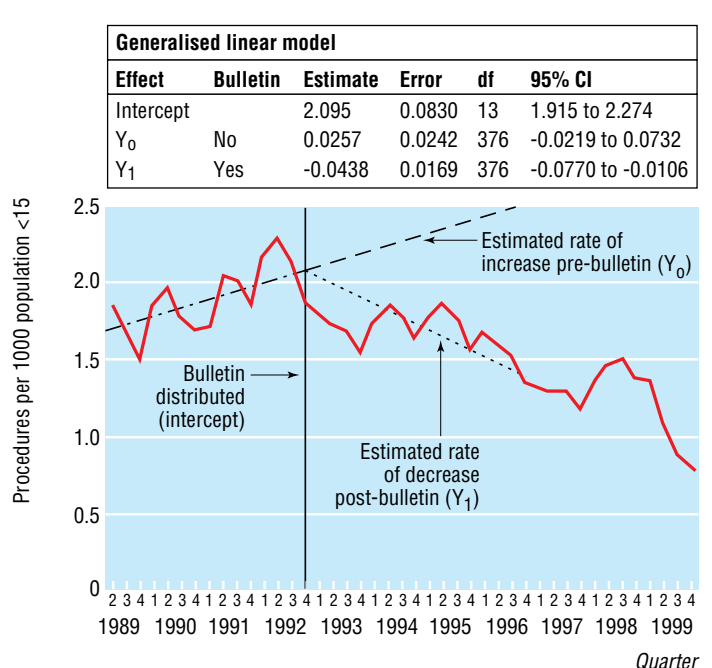

Quarterly rate of grommet insertions for glue ear per capita in England before and after distribution of the Effective Health Care bulletin on treatment of persistent glue ear

1000 children, with regional rates varying by a factor of two. A small increase in the quarterly rate of procedures per 1000 children during the three years before distribution of the bulletin (0.026 (95\% confidence interval -0.022 to 0.073$)$ ) became a decrease in the four years after publication $(-0.044$ $(-0.080$ to -0.011$) ; \mathrm{P}<0.0001)$ (figure). The decrease in quarterly rate from 1992 onwards was seen consistently across the regions.

The changing trend in surgery suggests that 89800 procedures were avoided nationally in the four years after the bulletin, providing a theoretical saving of $£ 27 \mathrm{~m}$ at 1992-3 prices. ${ }^{2}$ Regional variations in the numbers of surgical procedures undertaken were $30 \%$ smaller after distribution of the bulletin than before (SE $0.0169 v$ 0.0242). Our findings were not substantially altered by analysing procedures under the broader code D15 (drainage of the middle ear) or by age range.

\section{Comment}

Distributing printed recommendations to decision makers may influence surgery rates, since a trend towards a reduction in the number of grommet operations was seen after distribution of the bulletin. Rates for tonsillectomy-another elective procedure in the same specialty-increased steadily over the same period, suggesting that the change was specific to persistent glue ear and thus was related to the bulletin.

The change cannot be attributed to the bulletin alone, which was commissioned because of pre-existing concerns about appropriate use of the procedure. Its publication received coverage in the medical and academic press, ${ }^{4}$ possibly encouraging doctors to examine their own practices and bring about behavioural change.

Surgery rates were reduced, and there was an apparent improvement in the equality of care, but our results do not provide information on quality of care delivered by either general practitioners or surgeons. Adherence to watchful waiting principles may have promoted more appropriate (and reduced) patient selection; alternatively, primary care physicians alerted by media concerns may have reduced referral rates. Establishing the link between health service activity and quality of care remains difficult

The estimated savings from reduced surgery $(£ 27 \mathrm{~m})$ are considerably greater than the approximate production cost of the bulletin ( $£ 25000)$. Another bulletin addressing the prescribing of selective serotonin reuptake inhibitors demonstrated a similar profile of costs. $^{5}$ Although the apparent healthcare savings are impressive, the impact on health outcomes, costs of alternative care received by patients, and costs of other health promoting activities remain unknown.

Contributors: JM had the original idea for the study, helped with data analysis, drafted the paper, and acts as guarantor. NF designed and conducted the data analysis. JM, GB, and NF participated in interpreting the data and revising the paper.

Funding: Academic grant from Nuffield Trust for Research Policy Studies in Health Services, registered charity No 209201.

Competing interests: JM and NF were members of the research team that wrote the Effective Health Care Bulletin on the treatment of persistent glue ear in children, and GB was a specialist adviser to the research team. JM and NF were employees of the Universities of York and Leeds, respectively, which received funding for the Effective Health Care bulletin project from the Department of Health.

1 Black NA. Surgery for children-a modern epidemic. Lancet 1984;i:835-7. 2 The treatment of persistent glue ear in children. Effective Health Car 1992; No 4.

3 Department of Health. Health and personal social services statistics for England. London: HMSO, 1996.

4 Sheldon TA, Freemantle N, Browning GG, Maw AR, Mason JM, Song F Glue ear guidelines: time to act on the evidence. Lancet 1992;340:1324-5.

5 Mason J, Freemantle N, Young P. The effect of the distribution of Effective Health Care Bulletins on prescribing selective serotonin reuptake inhibitors in primary care. Health Trends 1998-9;30:120-2.

(Accepted 23 April 2001)

\title{
General outbreaks of infectious intestinal diseases linked with private residences in England and Wales, 1992-9: questionnaire study
}

\author{
Iain A Gillespie, Sarah J O’Brien, Goutam K Adak
}

The inception of the Food Standards Agency in April 2000 has given food safety issues a high public and political profile. Recently, concerns about food hygiene have focused on the home and, in particular, the possible transmission of infection via household items. ${ }^{1}$ To determine the causes of gastrointestinal infection associated with the home, we reviewed general outbreaks (outbreaks affecting more than one household) of infectious intestinal disease in England and Wales reported to the Public Health Laboratory Service
Correspondence to: S J O'Brien sobrien@phls.org.uk continued over

BMJ 2001;323:1097-8 